\title{
Verzeichnis der Autorinnen und Autoren
}

Jacques BARIÉTY (geb. 1930), bis zu seiner Emeritierung Professor für Neuere und Neueste Geschichte an der Universität Paris IV-Sorbonne

Ansbert BAUMANN (geb. 1967), Dr. phil., wissenschaftlicher Mitarbeiter am Seminar für Zeitgeschichte der Universität Tübingen

Hans Manfred Bock (geb. 1940), Professor für Politische Wissenschaften an der Universität Kassel

Werner BÜHRER (geb. 1950), Dr. habil., wissenschaftlicher Mitarbeiter am Institut für Sozialwissenschaften der TU München

Corine DEFRANCE (geb. 1966), Dr. habil., Forscherin am CNRS (IRICE-Paris)

RoBert FranK (geb. 1944), Professor für Neuere und Neueste Geschichte an der Universität Paris I-Sorbonne-Panthéon

Florence GAUZY (geb. 1968), Dr. phil., Wissenschaftliche Mitarbeiterin an der Deutschen Hochschule für Verwaltungswissenschaften Speyer

Hans-Dietrich GENSCHER (geb. 1927), Außenminister der Bundesrepublik Deutschland 1974-1992, Bundesvorsitzender der FDP 1974-1985

Ulrich LAPPENKÜPER (geb. 1959), Professor am Historischen Seminar der Universität Bonn

Colette MAZzucell (geb. 1962), Dr. phil., Forscherin am Institut für politische Wissenschaften der Columbia University New York und an "Sciences Pou Paris

Henri MÉNUDIER (geb. 1940), Professor für Germanistik am Institut d'Allemand d'Asnières der Universität Paris III-Sorbonne Nouvelle

Ulrich PFEIL (geb. 1966), Dr. habil., Historiker am DHI Paris

Hans-Peter SchWARZ (geb. 1934), bis zu seiner Emeritierung Professor für Wissenschaft von der Politik und Zeitgeschichte an der Universität Bonn

Andreas WILKENS (geb. 1957), Professor für Neuere und Neueste Geschichte an der Universität Metz 
